\title{
Towards a New Digital Game of Contemporary Aesthetics
}

\author{
leva Gintere \\ Vidzeme University of Applied Sciences
}

\section{INTRODUCTION}

This paper partly envisages the research results of the European Regional Development Fund (ERDF) project (see Acknowledgements). The task is to create an innovative digital game in the cross-cutting genres of art game and educational game. The game presents the specific aspects of digital art games and their historical background. Work on the new game will be carried out in a collaboration of the researcher, Dr.art. leva Gintere (Vidzeme University of Applied Sciences, Latvia) and the game artist, Mag.art. Kristaps Biters (Latvia). The game is being created in the framework of a Post-doctoral project led by leva Gintere during 2018-2021.

\section{MATERIALS AND METHODS}

Unity3d for game design. Blender 3d object design. Audacity and Abletone music generation and editing. Photoshop, illustrator for game texture, art design.

\section{RESULTS}

The study presents an insight into contemporary digital game theory and a new threefold method of game creation named RKTR (research / knowledge transfer / research). In this model, the game is created on the basis of research and knowledge transfer: knowledge gained in the research process is transferred to the players. The game also functions as a platform of new knowledge construction as the secondary task of the game is to collect the results of the players in order to analyse the new creative tendencies and to foresee the art trends of tomorrow.

The proposed method focused on the aspect of knowledge transfer is constructed as a three-level spiral:

- research-based game creation (the game is based on the results of research),

- knowledge transfer (the game transfers the research results to the player),

- use of the gameplay results in research (the game creators collect the data of the gameplay for new research).

The existing game designers and theoreticians carry out research in action where the game design is united with the game research. In the discourse of digital gaming, this is a widespread method. However, there is a missing part in this model. Knowledge gained in this type of research does not flow beyond the circle of the game's creators and researchers. This knowledge stays within the society of the game's designers and researchers, and functions as a tool for their future work. Knowledge is an instrument for experts, and it is not transferred to the regular player. The existing model of a research-based game helps to obtain formal and professional knowledge: it is a know-how, it tells a designer how to build a game, but it is not meant for the player. The aim of the new digital game that is being created in this project, is to connect the research results with the player so that the knowledge acquired in the research process is effectively transferred to the general public.

\section{DISCUSSION}

Taking into account that art today is largely interactive, the new art game will let its user play with trends of digital art such as noise, generative art and others, and to create new ones. The aim of this project is to raise the interest of a wide-ranging public for contemporary art and to point out the newest creative tendencies in art. The game would develop the creative skills of players and teach them the current trends in digital art. At the same time the game would project the inheritance of art from the age of modernism into the digital world by teaching the player to recognize it (for instance, generative art is a successor to the Fluxus movement in modernism). The new art game is intended to educate the player and to stimulate his/her creative forces.

The Design Science Research method is being used in this study in order to cross-cut such remote fields as the general public, the arthouse world, codes of modern art and the tastes of the general public. The Design Science Research method helps boost efficiency and interest towards contemporary art games. It intends to integrate seemingly distant disciplines and seeks parallels in different areas in order to gain new knowledge and adapt fresh approaches. By finding common aspects in different areas, Design Science Research fuses areas and invites new trends into a research field.

\section{ACKNOWLEDGEMENTS}

This study has been supported by a grant from the European Regional Development Fund research "Leveraging ICT product innovations by enhancing codes of modern art" No. 1.1.1.2/VIAA/1/16/106 within the Activity 1.1.1.2 "Post-doctoral Research Aid" of the Specific Aid Objective 1.1.1 "To increase the research and innovative capacity of scientific institutions in Latvia and the ability to attract external financing, investing in human resources and infrastructure" of the Operational Program "Growth and Employment". Homepage of the research: http://va.lv/en/research/research/leveraging-ict-product-innovations-enhancingcodes-modern-art.

\section{KEYWORDS}

Digital art game, methodology of digital games, knowledge transfer, aesthetics of modernism. 